\title{
O trabalho com uma sequência didática de receitas em língua inglesa em uma escola pública
}

\author{
Ana Paula Marques Beato-Canato* \\ Vera Lúcia Lopes Cristovão**
}

\begin{abstract}
Resumo
Em uma perspectiva interacionista sociodiscursiva, advogamos que, para alcançar seus objetivos, o trabalho com línguas na rede regular pública de ensino pode ser planejado em sequências didáticas organizadas em torno de gêneros textuais. Tais unidades visam ao desenvolvimento de capacidades de linguagem, entendidas como "aptidões requeridas para a realização de um texto numa situação de interação determinada" (DOLZ; PASQUIER; BRONCKART, 1993, p.30). A partir desses pressupostos, sequências didáticas foram aplicadas a alunos de uma escola municipal de Joinville, ao longo de um ano escolar, com o objetivo de possibilitar a participação efetiva em um projeto de troca de correspondências. Dentre os gêneros abordados, selecionamos receitas culinárias para o escopo deste artigo, que visa, assim, descrever o material elaborado e analisar as produções de um aluno de modo a ilustrar oportunidades (ou não) de desenvolvimento de capacidades de linguagem possibilitadas por um trabalho dessa natureza.

Palavras-chave: Interacionismo Sociodiscursivo; gênero textual receita culinária; sequência didática; ensinoaprendizagem de língua inglesa; desenvolvimento de capacidades de linguagem.
\end{abstract}

\section{The work with a didactic sequence of recipes in English as an additional language in a public school}

\begin{abstract}
In a sociodiscursive interactionist perspective, we advocate that, to achieve its goals, the work with languages in public regular schools can be planned in didactic sequences towards genres. Such units aim at the development of language capacities (DOLZ; PASQUIER; BRONCKART, 1993). Based on these principles, didactic sequences were employed with students of a public school in Joinville, during a school year, with the objective of contributing to their effective participation in a pen pal Project. Among the genres handled, cooking recipes were taken as scope of this paper, which aims at describing the material planned and analyze the productions of one student in order to illustrate the opportunities of language capacities development enabled by a work of this nature.

Keywords: Sociodiscursive Interacionism; genre cooking recipe; didactic sequences; English language teaching/ learning; language capacities development.
\end{abstract}

\section{Introdução}

Tornar o ensino de línguas estrangeiras mais significativo para o aluno tem sido objetivo de inúmeros professores que têm buscado trabalhar com gêneros textuais, conforme ilustram as obras organizadas por Dionísio, Machado e Bezerra (2005), Cristovão e Nascimento (2004; 2005), Karwoski, Gaydeczka e Brito (2005), Dias e Dell'Isola (2012), dentre tantas outras.

Segundo Schneuwly e Dolz (2004), o trabalho com línguas no ensino tem o objetivo de levar os alunos a dominar gêneros para que se adaptem e participem de forma mais efetiva na vida social/ comunicativa. Os autores (SCHNEUWLY; DOLZ, 2004) sugerem o planejamento organizado em sequências didáticas, que são conjuntos de atividades em torno de determinados gêneros que

\footnotetext{
* Endereço eletrônico: anabeato@uol.com.br

** Endereço eletrônico: veraluciacristovao@gmail.com
}

visam ao desenvolvimento de capacidades de linguagem, conceito que será discutido na seção de pressupostos teóricos.

A pesquisa de doutoramento de uma das autoras foi contextualizada no ensino fundamental, quando atuava como professora de língua inglesa de uma escola pública de Joinville (SC) e desenvolveu um projeto de troca de correspondências (pen pal) entre alunos de $7^{a}$. Séries de uma escola municipal brasileira e alunos norte-americanos. Para que o projeto se efetivasse, sequências didáticas foram produzidas e trabalhadas de modo a colaborar para a compreensão e produção de textos a serem trocados pelos envolvidos. Nesse processo, a participação dos alunos era efetiva e se concretizava inclusive na escolha dos gêneros textuais a serem produzidos e trocados.

Um dos gêneros selecionados pelos alunos 
brasileiros foi receita culinária para a produção de um livro de receitas, que permitiria compartilhar um pouco a respeito de hábitos alimentares dos grupos. Assim, uma sequência didática (SD) foi elaborada e trabalhada, com base nas dificuldades apresentadas pelos alunos ao produzir a primeira versão de uma receita (versão diagnóstica). Ao longo da unidade, os alunos revisaram seus textos em momentos distintos, e, no final do processo, os livros foram organizados e trocados entre os participantes.

No artigo, a SD será apresentada bem como a análise de receitas produzidas por um aluno, tendo como princípio a produção como processo, isto é, a produção sendo vista como uma construção em andamento, na qual várias versões de um mesmo texto podem ser feitas com base no que está sendo estudado. Nesse contexto, os gêneros textuais são vistos como "megainstrumentos", isto é, "como uma configuração estabilizada de vários subsistemas semióticos (sobretudo linguísticos, mas também paralinguísticos), permitindo agir eficazmente numa classe bem definida de situações de comunicação." (SCHNEUWLY, 2004, p.28) e as atividades formalizadas nas instituições são tidas como "fundamentais para a organização das aprendizagens em geral e para o processo de apropriação de gêneros em particular." (SCHNEUWLY; DOLZ, 2004, p.53).

Tal processo procura trazer subsídios tanto para o agir linguageiro (da ordem do saber dizer) quanto do agir praxiológico (da ordem do saber fazer) e, assim, contribuir para o aprimoramento da compreensão e da produção a partir de reflexões, questionamentos, discussões sobre o tema, os significados em sentido amplo, a organização do texto, sua adequação aos objetivos, as estruturas linguístico-discursivas empregadas, etc.

\section{Pressupostos teóricos}

Em uma perspectiva interacionista sociodiscursiva, entendemos gêneros como artefatos simbólicos disponíveis na sociedade que viabilizam a comunicação linguageira, por se constituírem como modelos de referência para nosso agir. Eles são criados e modificados continuamente nas interações humanas e podem ser tomados como instrumentos quando apropriados por nós e considerados úteis para nosso agir.

Adotando tal premissa, desde 1993, o grupo de Genebra (DOLZ; PASQUIER; BRONCKART, 1993; DOLZ; SCHNEUWLY, 1998) tem preconizado o trabalho com línguas organizado em torno de gêneros textuais significativos aos aprendizes de modo a colaborar para o desenvolvimento de uma prática que leve o aluno a atuar efetivamente na sociedade. Os pesquisadores propõem, assim, a produção de sequências didáticas, ou seja, conjuntos de atividades em torno de determinados gêneros textuais, que visem ao desenvolvimento de capacidades de linguagem. Estas, por sua vez, são definidas como "aptidões requeridas para a realização de um texto numa situação de interação determinada. (DOLZ; PASQUIER; BRONCKART, 1993, p.30)".

Apesar de as capacidades serem vistas como indissociáveis, os autores as dividem em três e as definem como:

- capacidades de ação: capacidades de adaptar-se às características do contexto e do referente;

- capacidades discursivas: capacidades de mobilizar modelos discursivos;

- capacidades linguístico-discursivas: capacidades de dominar as operações psicolinguísticas e as unidades linguísticas. (SCHNEUWLY; DOLZ, 2004, p.52)

Diversos pesquisadores brasileiros alinhados a essa perspectiva têm se dedicado a investigar práticas de ensino com base nesses princípios e, segundo Bawarshi e Reiff (2010, apud CRISTOVÃO, prelo), desenvolveram o que denominam a abordagem didática brasileira, que tem cinco preocupações em destaque: "caracterização da esfera em que o gênero circula; estudo da sócio-história do gênero e seu desenvolvimento; caracterização do contexto de produção; análise do conteúdo temático; e análise da construção composicional do gênero." (CRISTOVÃO, prelo).

Fazendo parte desse grupo brasileiro, temos discutido em nosso grupo de pesquisa (Linguagem e Educação), desde 2005, a necessidade de ampliação das capacidades de modo a evidenciar aspectos mais amplos em termos de atividade geral, de conjuntos e sistemas de gêneros, bem como de uma contribuição marcada para o quadro de intervenção didática. Como uma reação a esse quadro, propusemos (CRISTOVÃO; STUTZ, 2011) a capacidade de significação, que

possibilitam ao indivíduo construir sentido mediante representações elou conhecimentos sobre práticas sociais (contexto ideológico, histórico, sociocultural, econômico etc.) que envolvem 
esferas de atividade, atividades praxiológicas em interação com conteúdos temáticos de diferentes experiências humanas e suas relações com atividades de linguagem.

O trabalho sistematizado e preocupado em contribuir para o desenvolvimento das capacidades de linguagem nessa perspectiva mais ampla procura estabelecer relações entre as atividades propostas entre si e entre elas e a produção de significação. Nesse sentido, atividades aparentemente tradicionais se analisadas dentro desse conjunto mais amplo podem apresentar objetivos mais abrangentes e contribuir para a compreensão ou produção de textos de maneira mais consciente e crítica.

Ainda dentro da perspectiva adotada é relevante ressaltar que a revisão continuada das atividades planejadas é imprescindível em vistas a observar a necessidade de alterações, exclusões, inserções de modo a desenvolver um trabalho que de fato contribua para o desenvolvimento de capacidades de linguagem de todos os participantes e tome os gêneros textuais como instrumentos de aprendizagem e desenvolvimento, como explicado na introdução. Ademais, é primordial a compreensão das capacidades como uma engrenagem, isto é, um todo coerente e coeso, um conjunto de características/ aspectos que é separado apenas para fins didáticos. Nesse sentido, as atividades podem ser elaboradas enfocando capacidades diferentes, mas precisam a todo o momento exigir que as diversas capacidades sejam ativadas.

Com o objetivo de contribuir para que o trabalho com línguas estrangeiras também colabore para que os aprendizes ajam de forma mais efetiva na vida social/comunicativa, desde 2002, temos feito propostas e desenvolvido pesquisas com base nesses princípios (CRISTOVÃO, 2002; 2007; 2009; BEATO-CANATO, 2005; 2009; FERRARINI, 2006; 2009; PETRECHE, 2008) e temos percebido que a proposição pode ser efetiva de fato.

\section{O gênero receita culinária}

Uma busca bibliográfica sobre o gênero receita (culinária) foi realizada no momento de produção da SD, em 2006, e nenhum trabalho foi localizado em nenhuma das bases de dados online pesquisadas. Também não foram encontrados relatos de experiências desenvolvidas em sala de aula, apesar de ser um gênero comumente trabalhado, especialmente nas séries iniciais tanto em língua portuguesa quanto em língua estrangeira (ao menos nos contextos em que já atuamos). Posteriormente, encontramos o trabalho de Brait (2010), que aponta que,

de forma geral, além de indicar como selecionar e misturar ingredientes, permitindo que o leitor/ouvinte/cozinheiro produza pratos suculentos, nutritivos, saborosos, exóticos e até mesmo afrodisíacos, as receitas culinárias, enquanto texto e enquanto confluência de discursos, vão muito além de sua comportada função didática dominante. Produzidas em condições sociais, hábitos alimentares e linguísticos das pessoas e das sociedades em diferentes épocas, o papel da alimentação nas relações familiares $e$ sociais, os intercâmbios culinários entre povos e comunidades, os registros $e$ a circulação das diferentes formas que o homem encontra para transformar uma necessidade em arte de viver $e$, o que interessa aqui mais diretamente, elas expõem o estatuto de uma maneira de dizer que é também uma maneira de ser, o que, discursivamente, implica estilo, autoria, identidade e memória (BRAIT, 2010, p.199).

A pesquisadora também aponta que "a receita contemporânea padrão ainda apresenta os ingredientes e, depois, o modo de prepará-los" (BRAIT, 2010, p.207).

Historicamente, as receitas faziam parte do universo feminino, tendo em vista que cabia às mulheres a tarefa de cozinhar. Dessa maneira, fotos de mulheres cozinhando, por exemplo, eram muito comuns em livros de receitas, embalagens, rótulos e propagandas, e os programas de TV ou rádio eram sempre apresentados por mulheres e convidadas, com figurinos que faziam referência às donas de casa e com cenários que lembravam as cozinhas de nossas casas. A linguagem utilizada era coloquial, do cotidiano, e, geralmente, eram ensinadas receitas caseiras, com ingredientes relativamente fáceis de serem encontrados, procurando colaborar com o dia-a-dia da dona de casa, que era vista como a responsável pela alimentação de toda a família. Vale ainda mencionar que eram muito comuns as trocas de receitas entre mulheres, tanto verbalmente 
quanto por escrito, e que a coleção de receitas era um passatempo de muitas delas. Além disso, o ato de cozinhar era muito associado ao zelo familiar e as receitas revelavam muito dos hábitos familiares de uma família e eram diretamente relacionadas a questões emocionais, vínculos familiares, o que se revelava nos nomes dados a elas, tais como: bolo da vovó; biscoitinho da tia x; pãozinho da vovó, etc.

Ao longo do tempo, essa visão foi sendo modificada, talvez especialmente pela inserção feminina no mercado de trabalho, o que acarretou a expansão do hábito de alimentação fora de casa, seja no dia-a-dia seja em finais de semana ou datas especiais, ora por necessidade ora por comodismo, o que dissociou o ato de cozinhar de uma tarefa cotidiana das mulheres donas de casa. Atualmente, o gênero receita culinária circula em espaços mais variados, especialmente com a popularização da internet, e a tarefa de cozinhar não é mais associada exclusivamente às mulheres. Consequentemente, livros de receitas, materiais publicitários e programas de TV dissociam o gênero de texto ao gênero feminino e inserem cada vez mais programas relacionados ao tema com apresentadores masculinos, sejam chefes de cozinha sejam amantes do ato de cozinhar. Ademais, é possível dizer que a atividade de cozinhar passou a ser associada ao lazer e tem sido relacionada ao requinte, com a divulgação cada vez mais comum de pratos elaborados por chefes de cozinha, por exemplo. Assim, as receitas têm se dissociado de questões familiares e afetivas e seus nomes, consequentemente, têm também se distanciado desse campo semântico. Paralelamente a esse processo, é comum também o movimento inverso, o de valorização de comidas tradicionais e familiares, porém, com status diferente do atribuído a elas no passado, sendo associadas atualmente a questões afetivas e não a obrigações femininas.

No caso do projeto, destacamos a ancoragem cultural que receitas culinárias veiculam e a possibilidade de acesso a um tipo de bem cultural de um povo que a troca de livros de receita facilitou.

Com relação à organização, os textos, especialmente escritos, apresentam sequência injuntiva, isto é, são textos sustentados por um objetivo próprio ou autônomo: fazer agir o destinatário de uma certa maneira (BRONCKART, 2003). Esse objetivo exerce efeitos sobre as propriedades da sequência (presença de formas verbais no imperativo ou no infinitivo; ausência de estruturação espacial ou hierárquica, etc.). No caso de receitas, o objetivo é guiar o leitor no preparo de determinado alimento. Para isso, é preciso seguir os passos dados.

Quanto à constituição, há alguns elementos essenciais, que são nome da receita, lista de ingredientes, quantidade e modo de preparo. Em algumas delas, aparecem também o autor da receita, o tempo de preparo, o grau de dificuldade, a quantidade de porções e uma figura ilustrativa. Esses outros elementos aparecem em receitas publicadas, mas dificilmente estão presentes em receitas trocadas entre pessoas comuns. No caso da internet, há diversas receitas com figuras ou vídeos que ilustram os passos.

A apresentação dos ingredientes e da quantidade necessária é feita em forma de uma lista na qual a quantidade aparece primeiro seguida do ingrediente e, no modo de preparo, o imperativo é utilizado indicando os passos necessários para a produção do alimento.

Em receitas no Brasil, em português, especialmente nas trocadas entre pessoas comuns, é corrente o uso do infinitivo nas instruções como em: "fazer uma massa...", "deixar na geladeira". Na busca realizada em receitas em inglês na internet, não foi encontrada nenhuma receita que apresentasse enunciados com construções como essas, apenas com o imperativo.

Os textos trabalhados na SD eram retirados da internet, mas as produções dos alunos foram de receitas familiares. Assim, foi possível valorizar o que é local, familiar, em contraste com o que é tradicional em outras partes do mundo. Isso foi tido como uma premissa na elaboração da SD, especialmente por se tratar de um contexto de ensino-aprendizagem de língua estrangeira dentro de um projeto de troca de correspondências. Isso para tentar oportunizar discussões sobre diferentes hábitos e a conscientização sobre as diferenças e sobre a cultura local.

\section{Metodologia}

A partir dos pressupostos apresentados anteriormente, um projeto de troca de correspondências foi desenvolvido ao longo do ano de 2006 entre alunos de 7as. séries de uma escola municipal de ensino de Joinville e uma escola norteamericana de Chesapeake, cidade-irmã ${ }^{1}$ de Joinville. $^{2}$

A seleção dos gêneros contou, na medida do possível, com a participação dos alunos, tendo sido receitas um dos gêneros sugeridos por eles, devido à 
curiosidade quanto aos hábitos alimentares dos norte-americanos. Assim, o gênero receita foi inserido no programa de ensino da disciplina e uma SD em torno do gênero foi produzida e trabalhada, tendo como objetivos desenvolver a compreensão e produção escrita de receitas e refletir sobre hábitos alimentares em diferentes partes do mundo. Para isso, ao longo da unidade, diferentes receitas (australiana, britânica, italiana e mexicana) foram lidas e discutidas e textos foram produzidos pelos alunos, resultando num livro de receitas, que foi enviado aos Estados Unidos.

A seguir o contexto de desenvolvimento do trabalho será descrito bem como a SD com comentários com relação a seu trabalho em sala de aula, para, em seguida, apresentar os procedimentos de coleta de dados e de análise.

\subsection{Contexto}

O projeto foi desenvolvido com alunos de $7^{\mathrm{a}}$ série de uma escola municipal de Joinville (SC), localizada em um bairro de classe média-baixa/ baixa. A sala era constituída por trinta e dois alunos, sendo quatorze meninos e dezoito meninas. A média de idade dos estudantes era de doze-quatorze anos.

O corpo docente julgava a turma imatura, desinteressada e descomprometida com a escola, sendo, portanto, complicado o trabalho. Havia muitos alunos com reputação de indisciplinados, que causavam problemas não apenas em sala de aula, pois estavam frequentemente envolvidos em brigas e vandalismo.

Durante as aulas de inglês, os problemas enfrentados eram conversas paralelas e falta de compromisso. Muitos alunos só realizavam as atividades desenvolvidas em sala e alguns nem mesmo essas atividades.

Entretanto, a motivação para o estudo por causa da troca de correspondências fazia com que buscassem desenvolver boa parte das atividades, pois tinham interesse em compreender os textos recebidos e, especialmente, realizar suas produções adequadamente para enviarem a seus amigos por correspondência.

A professora-pesquisadora foi responsável pelo material utilizado em sala, tendo como objeto de estudo o desenvolvimento da escrita com o trabalho com SD que possibilitasse a troca de correspondências de forma efetiva.

\subsection{A SD Learning recipes from different parts of the world}

Como dito anteriormente, a SD foi elaborada atendendo a uma expectativa dos alunos. Aqui, descrevemos as atividades propostas e tecemos comentários sobre elas à luz das capacidades de linguagem.

Primeiramente, foram estabelecidos quatro objetivos para o desenvolvimento do material, sendo eles:

- desenvolver a compreensão e a produção escrita de receitas culinárias em língua inglesa;

- discutir sobre hábitos alimentares de diferentes partes do mundo, compreendendo e respeitando as diferenças;

- aprofundar conhecimentos linguísticodiscursivos relacionados a instruções e receitas culinárias (imperativo; léxico relacionado; medidas);

- criar um livro de receitas brasileiras a ser enviado aos Estados Unidos.

A primeira parte da SD é denominada Tasting and learning an Australian recipe. Ela foi elaborada como forma de mobilização, da seguinte maneira: um doce australiano foi levado para a sala e distribuído entre os alunos, que o provaram e realizaram as atividades abaixo:

$$
\begin{aligned}
& \text { a- Qual o nome da receita? } \\
& \text { ( ) chocolate pudding ( ) chocolate mousse ( ) chocolate fudge } \\
& \text { ( ) chocolate ice cream ( ) chocolate cake ( ) chocolate muffin } \\
& \text { b- } \quad \text { Para fazer a receita, são necessários apenas } 4 \text { ingredientes. Pelo sabor, pela textura e pela aparência, } \\
& \text { ( ) condensed milk ( ) single milk ( ) salt } \quad(\quad) \text { oil ( ) baking powder } \\
& \text { ( ) butter ( ) wheat flour ( ) sugar ( ) pepper ( ) clove garlic } \\
& \text { c- Abaixo, você encontra as quantidades necessárias para fazer a receita. Escreva os ingredientes: }
\end{aligned}
$$

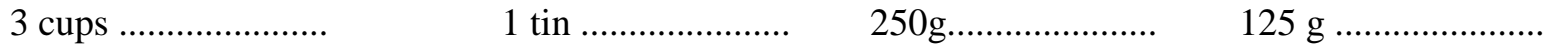


d- $\quad$ Agora que você já sabe os ingredientes e as quantidades, chegou a hora de aprender como fazer a receita. Comece procurando no dicionário o significado dos verbos abaixo: place; add; stir; melt; microwave; refrigerate.

e- $\quad$ Coloque as instruções em ordem. A primeira está feita para você.

(1 ) Place all ingredients except for the chocolate in a glass bowl.

( ) Add chocolate pieces and stir through until the chocolate is all melted.

( ) Microwave on high for 3 minutes and stir.

( ) Microwave again for another 3 minutes.

( ) Microwave for a further minute.

( ) Refrigerate and then cut in squares.

f- $\quad$ Você acha que é fácil fazer a receita? Por quê?

g- Será que é possível fazê-la no fogão? Quanto tempo levaria?

Após a mobilização com atividades focadas na organização do gênero e em léxico, a proposta de elaboração de um livro de receitas foi colocada aos alunos e um índice com as receitas que acrescentariam ao livro foi feito. Em grupos de quatro, os estudantes produziram uma receita, denominada diagnóstica, ou seja, que serviria para que o professor e os próprios alunos pudessem perceber as necessidades de trabalho, como proposto por Schneuwly e Dolz (2004). A receita de arroz foi selecionada para essa atividade pelos próprios alunos, por dois motivos: 1) essa receita não faria parte do livro de receitas; 2) é uma receita tipicamente brasileira.

No momento de produção do texto, houve a reflexão sobre o gênero e a percepção de que a maioria dos estudantes familiarizada com o gênero era do sexo feminino, o que levantou a questão sobre preconceitos e associação de tarefas domésticas ao gênero feminino. Tal discussão está relacionada à capacidade de significação, pois extrapola os limites do texto e repercute na visão de mundo e de si dos participantes e nas concepções relacionadas à situação de comunicação em questão.

A parte seguinte do material ocupou-se com o léxico utilizado em receitas. Por isso, foi intitulada Learning some important words related to recipes. A atividade propunha aos alunos que, usando as receitas que tinham no material (Guacamole, Penne with mozzarella, chocolate fudge e Muffin), separassem as palavras dadas em duas listas, uma de ingredientes e outra de palavras relacionadas à quantidade. As palavras do quadro eram as seguintes: sugar, gram, oil, tin, spices, pepper, butter, pot, tomato, salt, pound, cheese, wheat flour, cup, milk, onion, teaspoon, liter, bottle, baking powder, condensed milk, single milk, tablespoon, box, glass, kilo. A atividade buscou mobilizar a capacidade discursiva juntamente com a linguístico- discursiva da seguinte maneira: o aluno familiarizado com o formato de uma receita facilmente identificaria as palavras relacionadas à quantidade e os ingredientes pela posição em que ocupavam na receita. Assim, o trabalho seria facilitado. Para aqueles que não conheciam o gênero, foi uma tentativa de levá-los a perceber sua estrutura. Nesse momento, o trabalho coletivo possibilitou trocas de informações dos menos familiarizados com o gênero com os mais acostumados.

Ainda tratando de medida, uma tabela de conversão foi discutida. Isso porque os alunos geralmente apresentam surpresa com o novo e sempre consideram o que é de conhecimento deles mais fácil. Com o quadro, foi possível mostrar que o que é fácil para eles pode não ser para outros. No quadro, havia a conversão da medida usada mais comumente aqui no Brasil para a conversão mais usada nos Estados Unidos (porque era com norteamericanos que trocariam receitas) e o inverso também. Novamente, vemos aqui a possibilidade de extrapolação do texto para o agir praxiológico, na medida em que o aprendiz teve a oportunidade de refletir sobre diferentes medidas e notar que não há uma única maneira de fazer isso, muito menos uma melhor ou mais fácil, mas sim que depende de como aprendemos, como nosso meio faz.

Após essa etapa, finalmente os alunos produziram a primeira parte de suas receitas a partir da versão em português trazidas por eles para a sala de aula. Essa parte foi intitulada Writing your recipe e a tarefa proposta foi que escrevessem, em inglês, o título da receita, os ingredientes e as quantidades necessárias para fazê-la, trabalhando, assim, as capacidades discursiva e linguístico-discursiva. Ainda nesse momento, houve espaço para discussão das receitas trazidas e reflexão sobre hábitos alimentares, sobre a possibilidade de execução de 
determinada receita em outros países devido aos ingredientes necessários.

A quarta parte da SD ocupou-se dos verbos mais utilizados em receitas. A atividade desenvolvida foi de ligar os verbos em inglês com as figuras correspondentes, atividade que exigiu o uso de dicionário. Os verbos trabalhados foram encontrados no link $<$ http://en.lernu.net/lernado/vortoj/bildvortaro/30.ph p>, em agosto de 2006, e são: cut, whisk, slice, cook, chop, boil, grill, bake, fry, stir, grate, open the tin, pour, peel, break an egg. Após a realização e correção da atividade, um jogo de mímica foi feito com a sala toda para a prática desses verbos de modo descontraído. Aparentemente, a atividade é exclusivamente de vocabulário e não se distingue de atividades propostas tradicionalmente. Porém, a nosso ver, quando inseridas no contexto de uma SD, podem ser avaliadas como contextualizadas e auxiliares no desenvolvimento da capacidade linguístico-discursiva.

A seção seguinte é denominada Reading some recipes e, como o nome sugere, as atividades realizadas propiciavam a compreensão escrita de receitas. Foram selecionados quatro textos, cujos nomes já foram citados anteriormente, tendo dois critérios: que fossem de países diferentes e que fossem possíveis de serem feitas aqui no Brasil, ou seja, que todos os ingredientes das receitas fossem possíveis de serem encontrados aqui.

A primeira atividade proposta era a de numerar os títulos de acordo com os textos das receitas, o que era feito por campo semântico. A segunda era para identificar quais receitas eram salgadas, quais eram doces e a terceira atividade era a de identificar a origem das receitas. Essa atividade foi feita como lição de casa e os alunos perguntaram a familiares, amigos e outros professores a resposta, extrapolando assim o âmbito escolar.
As atividades de quatro a sete eram pessoais, sendo três perguntas: 4- Qual receita salgada parece mais saborosa para você? Por quê? 5- Qual receita doce parece mais saborosa para você? Por quê? 6- Qual receita parece mais estranha para você? Por quê? 7- O que será que influencia nossos hábitos alimentares? Tais questões permitiram não apenas a leitura das receitas para compreensão, mas também uma análise (para decidir quais eram melhores/ piores/ mais estranhas para cada um deles) e ainda o conhecimento, a reflexão sobre hábitos de outras culturas e a tomada de posição. Logo após a discussão, foi lido um quadro denominado Você sabia?, no qual havia informação sobre a discussão feita previamente.

Defendemos que desde as receitas selecionadas às atividades desenvolvidas foram providos subsídios para o desenvolvimento de capacidades de linguagem, por facultarem ponderações sobre condições sociais, hábitos alimentares, relações familiares e sociais, maneiras de dizer, de ser (BRAIT, 2010, p.199) em contraste com suas próprias condições, hábitos, relações e maneiras de dizer e de ser. A avaliação das receitas e a discussão sobre isso, por exemplo, colabora para que o aluno se conscientize de como avaliamos, a partir de quais critérios, e de como nossas escolhas e hábitos, aparentemente pessoais, são atravessadas por questões sociais.

A parte seguinte foi de compreensão e análise de receitas, por isso, intitulada Analyzing some recipes. A primeira atividade proposta era a de observação das receitas para responderem à pergunta: $\mathrm{O}$ que as receitas têm em comum? A intenção era que os alunos percebessem as partes constitutivas das receitas bem como a linguagem utilizada em sua produção. As outras duas atividades propostas trabalhavam a constituição das receitas e foram as seguintes:

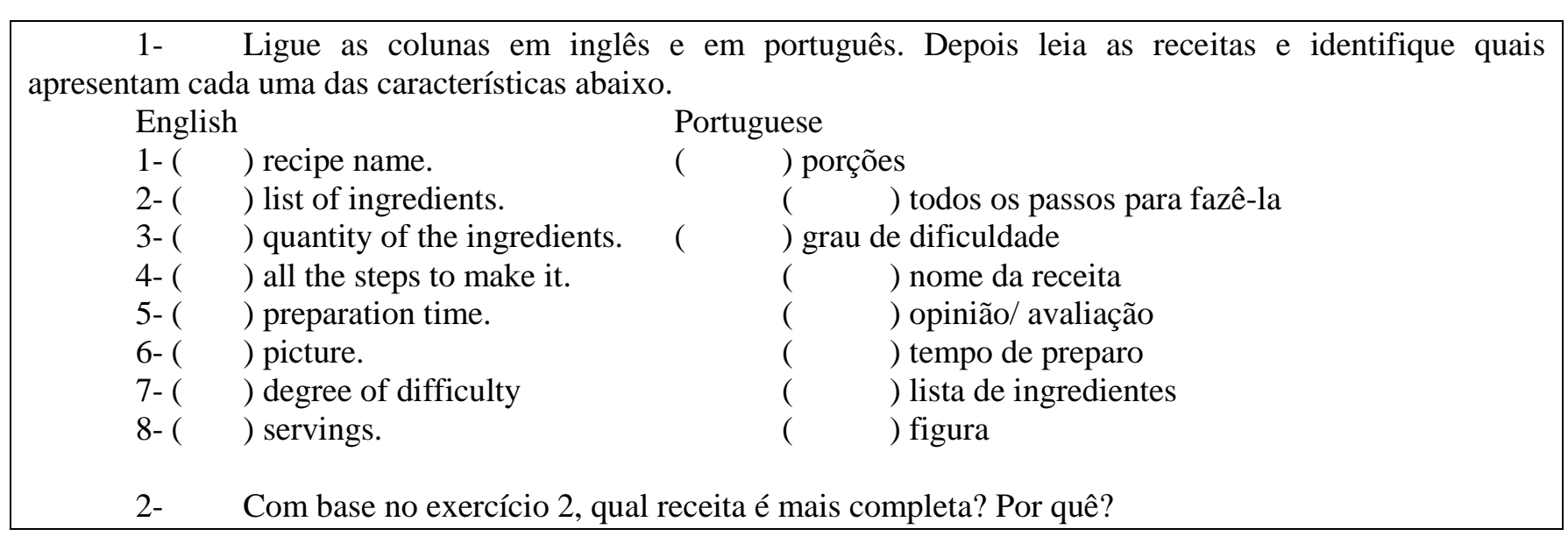


Retomando o que advogamos nos pressupostos teóricos, qualquer atividade se tomada isoladamente pode ser vista como uma proposta tradicional, porém, se analisada no conjunto, acreditamos poder trazer contribuições. A nosso ver, esse é o caso das atividades acima, que aparentemente não se diferem da abordagem tradicional ao exigir a simples tradução, com base especialmente nos conhecimentos da língua materna. Tomada no conjunto, é possível notar que ela contribui para que o aprendiz iniciante diminua sua ansiedade na leitura em língua estrangeira ao notar as similaridades entre as línguas, ao mesmo tempo que deve atentar para a organização das receitas lidas e observar seus elementos constitutivos, ou seja, mobilizar conhecimentos referentes às capacidades discursiva (organização) e linguístico-discursiva (léxico), o que em língua estrangeira supomos pertinente. No caso específico dessa SD, justificamos a inserção de atividades de tradução pelas seguintes razões: i) o pequeno número de aulas disponíveis; ii) a recorrência em seu uso (tanto por alunos quanto por professores) e a necessidade, por essa razão, de discutir sua necessidade ou não e o tipo de benefício que pode ou não trazer. Ou seja, uma possibilidade de tomada de consciência por parte dos alunos em termos de estratégias de aprendizagem.

A parte 6 era intitulada Comparing recipes instructions to games instructions e tinha como objetivo levar os alunos a perceberem as semelhanças entre instruções com fins diferentes. Isso porque a SD de instrução de jogos havia sido trabalhada anteriormente e a sequência injuntiva já havia sido estudada. Além disso, como apontam Schneuwly e Dolz (2004), os conhecimentos adquiridos ao longo do trabalho com uma SD precisam extrapolar o âmbito do gênero enfocado para que os aprendizes desenvolvam capacidades de linguagem para atuar em outros contextos. As atividades propostas foram as seguintes:

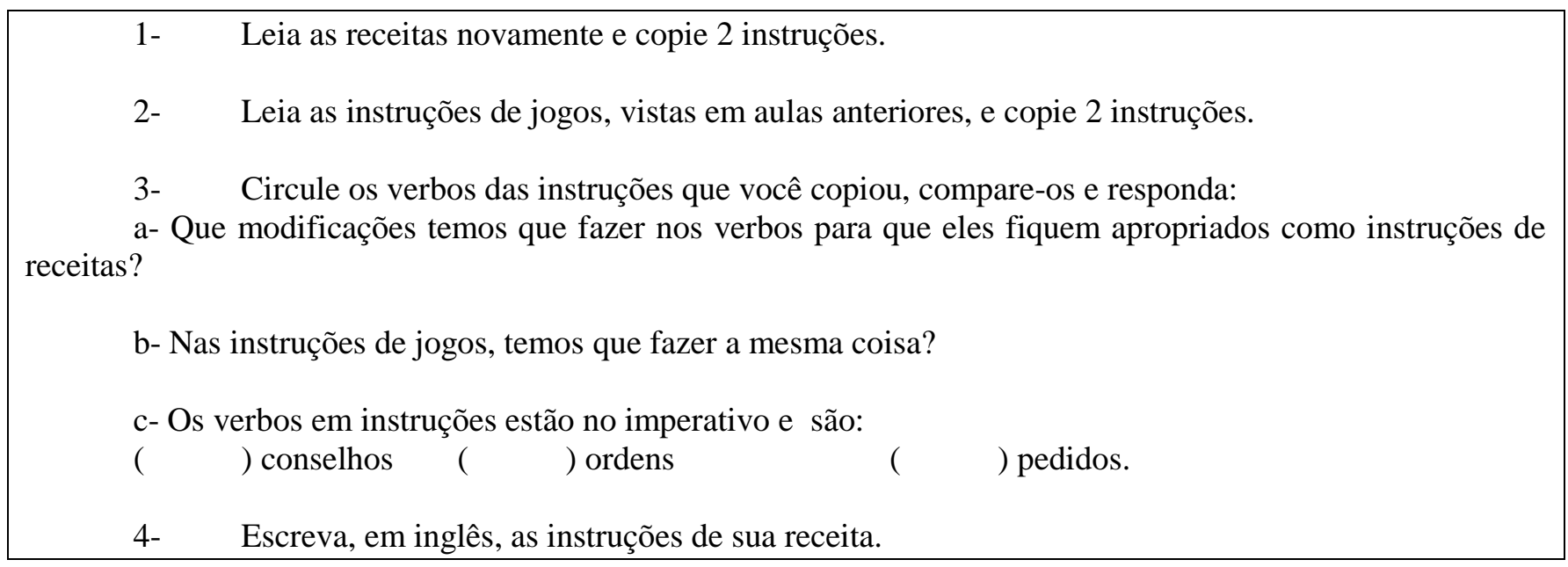

Nesse momento, foi possível discutir diferentes objetivos de sequências injuntivas, questões de poder associadas a elas, diferenças entre conselhos, ordens e pedidos, contribuindo com a compreensão da estrutura e, especialmente, de seus objetivos, e propiciar a generalização sobre essa sequência, o que é apontado por Schneuwly e Dolz (2004) como essencial no trabalho com gêneros textuais.

Finalmente a última seção da SD ocupou-se da produção final. A tarefa era unir as partes já produzidas, revisá-las e escrevê-las em uma folha de papel A4, com $2 \mathrm{~cm}$ de margem, para que pudesse ser encadernada no livro de receitas.

Consideramos que as atividades, embora simples, tinham relações entre si e foram organizadas de modo integrado, permitindo uma compreensão do gênero associado a questões socioeconômica-culturais e a maneiras de dizer, de ser, como aponta Brait (2010). Também avaliamos que houve mobilização de conhecimentos prévios, oportunidades de estabelecimento de relações entre textos na língua materna e na língua adicional (defendemos que essa estratégia facilita a compreensão), compreensão e aprofundamento da materialidade textual do gênero, ampliação de conhecimentos de campos semânticos específicos, ampliação da noção de sequência injuntiva, o que nos leva a concluir que o material trouxe subsídios para o desenvolvimento de capacidades de linguagem dos aprendizes. 


\subsection{Procedimentos de coleta e análise dos dados}

Como mencionado anteriormente, a SD foi utilizada dentro do um contexto mais amplo, de um projeto de troca de correspondências, com um ano de duração. A SD em análise foi realizada em quatro aulas de cinquenta minutos cada e contou com a participação média de trinta alunos.

Ainda como já dito, as produções a serem analisadas são quatro, sendo duas coletivas e duas individuais. A produção coletiva é de uma receita de arroz e a produção individual é de receita de pão de queijo. Foram coletadas sete versões tanto iniciais quanto finais de receitas de arroz. Com relação às versões individuais, foram coletadas dezenove produções iniciais e vinte produções finais, não necessariamente dos mesmos alunos.

O critério de seleção do corpus foi a produção e entrega de todas as versões solicitadas pelo professor de ambas receitas. A partir desse parâmetro, restaram as produções de um grupo e de um aluno, coincidentemente do grupo com menor grau de dificuldade. A quantidade pequena de dados para análise se deveu ao fato de os dados terem sido coletados ao longo do desenvolvimento da SD e muitos alunos não entregarem algumas versões, ou por terem faltado à aula, ou por não terem finalizado.

A partir desse parâmetro, notamos que, a princípio, analisaríamos as produções de alunos com menor dificuldade. Não vimos isso como um problema; ao contrário, assumimos como uma oportunidade de contemplá-los em uma pesquisa dessa natureza, que geralmente ocupa-se com estudantes com maiores dificuldades. Além disso, tomamos como uma ocasião de refletir sobre alterações no material de modo a alcançar as necessidades de todos os envolvidos.

Ao longo do trabalho, correções na primeira versão foram realizadas, mas não foram entregues ao professor. Assim, a análise dos dados se restringiu a quatro textos: 1) primeira versão da receita de arroz; 2) primeira versão da receita para o livro; 3) versão final da receita para o livro; 4) versão final da receita de arroz.

A análise dos textos foi feita com base em uma lista de constatação ${ }^{3}$, produzida pelo professor em conjunto com os alunos, bem como nas capacidades de linguagem.

\section{Análise dos dados}

No quadro a seguir (figura 1), a primeira produção de receita dos alunos é exposta. No lado esquerdo, há a versão original e, no lado direito, há a versão digitada para ser melhor visualizada. Logo em seguida, há uma tabela com a lista de constatação de receitas e a análise da produção dos alunos a partir dela.

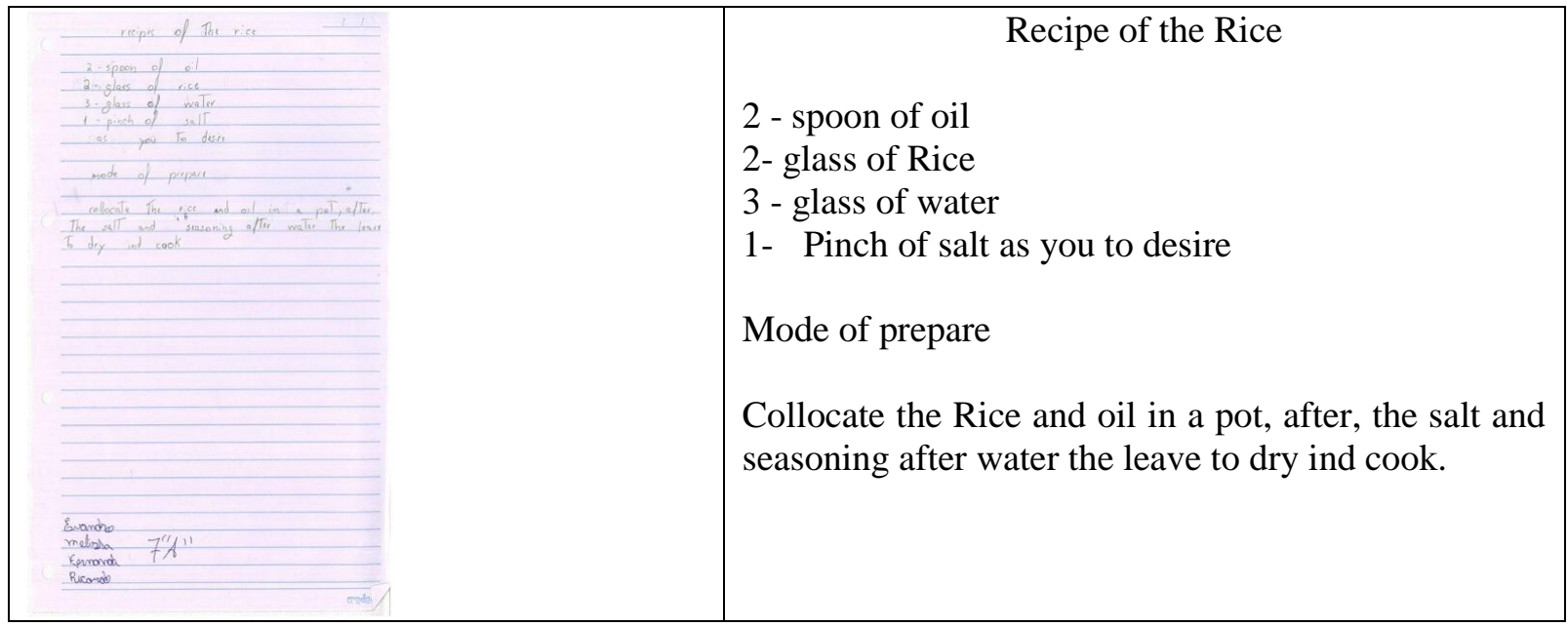

Figura 1: Receita de arroz 1 produzida em grupo

\begin{tabular}{|c|c|}
\hline Lista de constatação & Análise da receita 1 a partir da lista \\
\hline $\begin{array}{l}\text { Objetivo de fazer o destinatário agir de uma } \\
\text { determinada maneira (seguir os passos da receita) }\end{array}$ & $\begin{array}{l}\text { Conhecimento do objetivo de uma receita e } \\
\text { produção parcialmente adequada a seu objetivo. }\end{array}$ \\
\hline $\begin{array}{l}\text { Partes constitutivas essenciais: nome da receita; } \\
\text { lista de ingredientes com quantidade necessária } \\
\text { (que aparece antes do ingrediente, seguida por ele }\end{array}$ & Contemplação de todos os itens essenciais. \\
\hline
\end{tabular}




\begin{tabular}{|l|l|}
\hline $\begin{array}{l}\text { sem a preposição de ligação de); modo de } \\
\text { preparo. }\end{array}$ & \\
\hline $\begin{array}{l}\text { Elementos não essenciais (autor da receita, o } \\
\text { tempo de preparo, o grau de dificuldade, a } \\
\text { quantidade de porções e uma figura ilustrativa) }\end{array}$ & Ausência de itens não essenciais. \\
\hline Uso de imperativo no modo de preparo. & $\begin{array}{l}\text { Imperativo foi empregado para dar instruções; } \\
\text { uso inapropriado do artigo the antes do verbo } \\
\text { leave (deixar). }\end{array}$ \\
\hline Uso de léxico & $\begin{array}{l}\text { Uso lexical com forte influência da língua } \\
\text { portuguesa; sensível uso de dicionário e tradução } \\
\text { literal. }\end{array}$ \\
\hline
\end{tabular}

Quadro 1: Análise da receita de arroz 1 produzida em grupo a partir da lista de constatação

A análise realizada permite dizer que os alunos tinham conhecimento do gênero receita culinária, de seu contexto de uso e suas partes constitutivas. Foram capazes de, em língua inglesa, produzir uma receita de arroz satisfatória, com as seguintes dificuldades:

- tradução literal do português para o inglês, com busca em dicionário de palavra por palavra, em: "Recipe of the Rice" (receita de arroz), "pinch of salt as you to desire" (pitada de sal como você desejar, com o to de infinitivo do verbo), "Mode of prepare" (modo de preparo), "collocate" (coloque), "pot" para panela;

- dificuldade para dar a última instrução, que só pode ser compreendida por nós devido a nosso conhecimento da receita.

O fato de a parte final estar confusa também pode ser explicado, além da complexidade da construção do enunciado, por falta de tempo, já que tiveram apenas trinta minutos para produzirem seus textos. Isso porque, ao fazer a tradução literal e linear, os estudantes possivelmente dedicaram-se na primeira parte da produção e, por falta de tempo, escreveram a parte final sem ter havido espaço para discussão.

Conforme já explicado na parte de descrição da SD, após o trabalho em grupo e algumas atividades para o aprimoramento lexical (ingredientes e palavras referentes à quantidade), os estudantes produziram a primeira versão da receita individualmente, que seria acrescentada ao livro de receitas. No final da $\mathrm{SD}$, os integrantes dos grupos iniciais se reuniram novamente para produzir uma nova versão da receita de arroz com o intuito de possibilitar que eles próprios avaliassem o desenvolvimento que tiveram ao longo da SD.

A seguir, a versão inicial da receita do aluno e a análise:

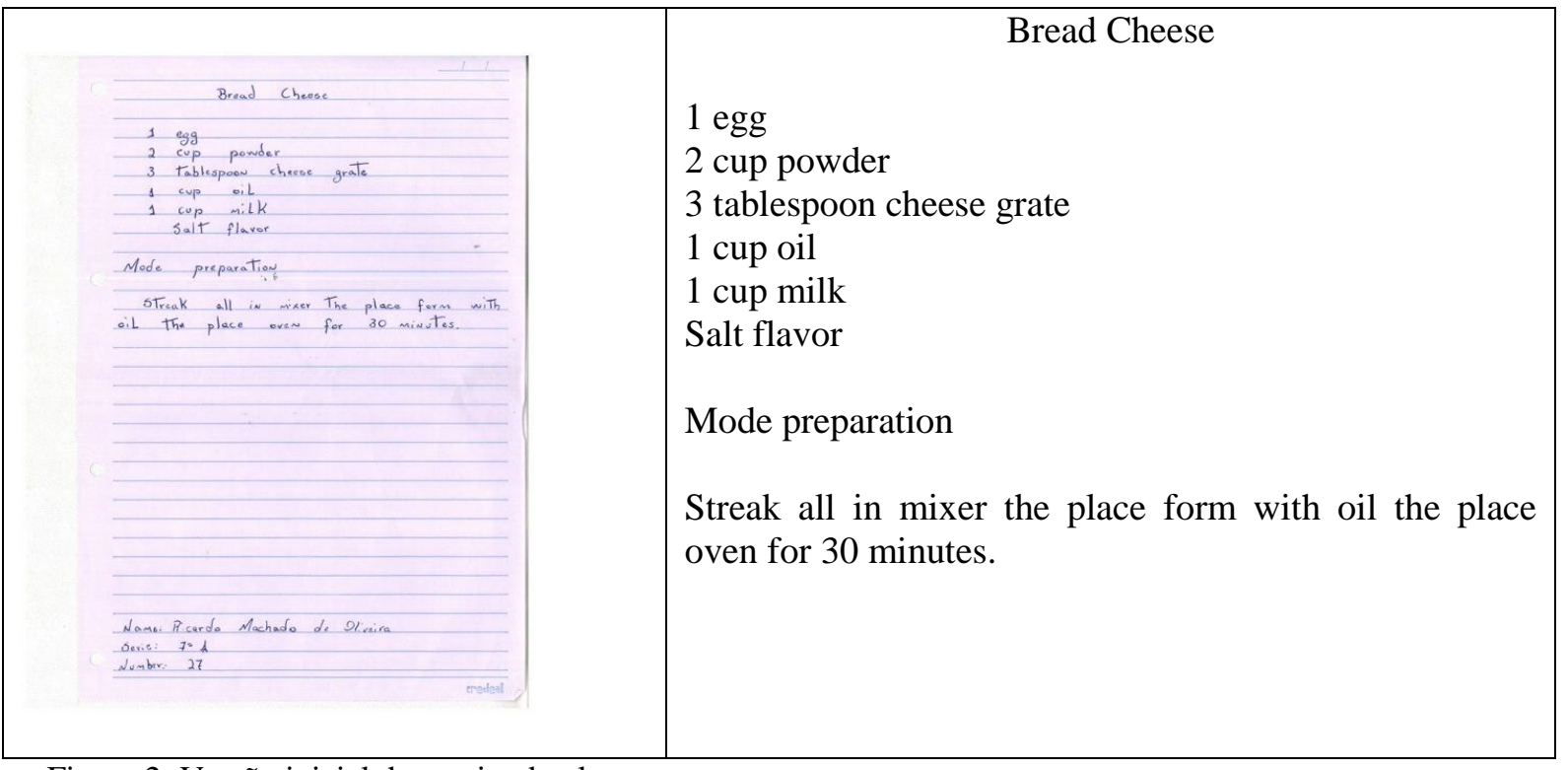

Figura 2: Versão inicial da receita do aluno 
Com base na lista de constatação, no quadro

a seguir, a produção inicial do aluno é analisada.

\begin{tabular}{|c|c|}
\hline Lista de constatação & $\begin{array}{l}\text { Análise da primeira versão da receita do aluno a } \\
\text { partir da lista de constatação }\end{array}$ \\
\hline $\begin{array}{l}\text { Objetivo de fazer o destinatário agir de uma } \\
\text { determinada maneira (seguir os passos da receita) }\end{array}$ & $\begin{array}{l}\text { Demonstra conhecimento dos objetivos de uma } \\
\text { receita e produção adequada a seu objetivo, com } \\
\text { poucas alterações necessárias. }\end{array}$ \\
\hline $\begin{array}{l}\text { Partes constitutivas essenciais: nome da receita; } \\
\text { lista de ingredientes com quantidade necessária } \\
\text { (que aparece antes do ingrediente, seguida por ele } \\
\text { sem a preposição de ligação de); modo de } \\
\text { preparo. }\end{array}$ & Contemplação de todos os itens essenciais \\
\hline $\begin{array}{l}\text { Elementos não essenciais (autor da receita, o } \\
\text { tempo de preparo, o grau de dificuldade, a } \\
\text { quantidade de porções e uma figura ilustrativa) }\end{array}$ & Ausência de itens não essenciais. \\
\hline Uso de imperativo no modo de preparo. & $\begin{array}{l}\text { Emprego de imperativo para dar instruções, } \\
\text { porém, com dificuldades para construir o texto } \\
\text { em língua inglesa. }\end{array}$ \\
\hline Uso de léxico & $\begin{array}{l}\text { Forte influência da língua portuguesa, sendo } \\
\text { possível perceber a busca constante no dicionário } \\
\text { para tradução. }\end{array}$ \\
\hline
\end{tabular}

Quadro 2: Análise da primeira versão da receita do aluno a partir da lista de constatação

Comparando essa produção ao texto escrito em grupo, é plausível ponderar que, em relação ao contexto e ao modelo discursivo, as produções se assemelham. Entretanto, o aluno apresentou maiores dificuldades em redigir o texto ao fazê-lo individualmente, apesar de ser considerado o melhor aluno do grupo, o que apresenta maior interesse, compromisso e conhecimento da língua também. Isso confirma a importância do trabalho coletivo em sala de aula para o desenvolvimento de todos.

No próximo quadro, a versão final da receita individual é apresentada seguida da análise, realizada com base na lista de constatação elaborada.

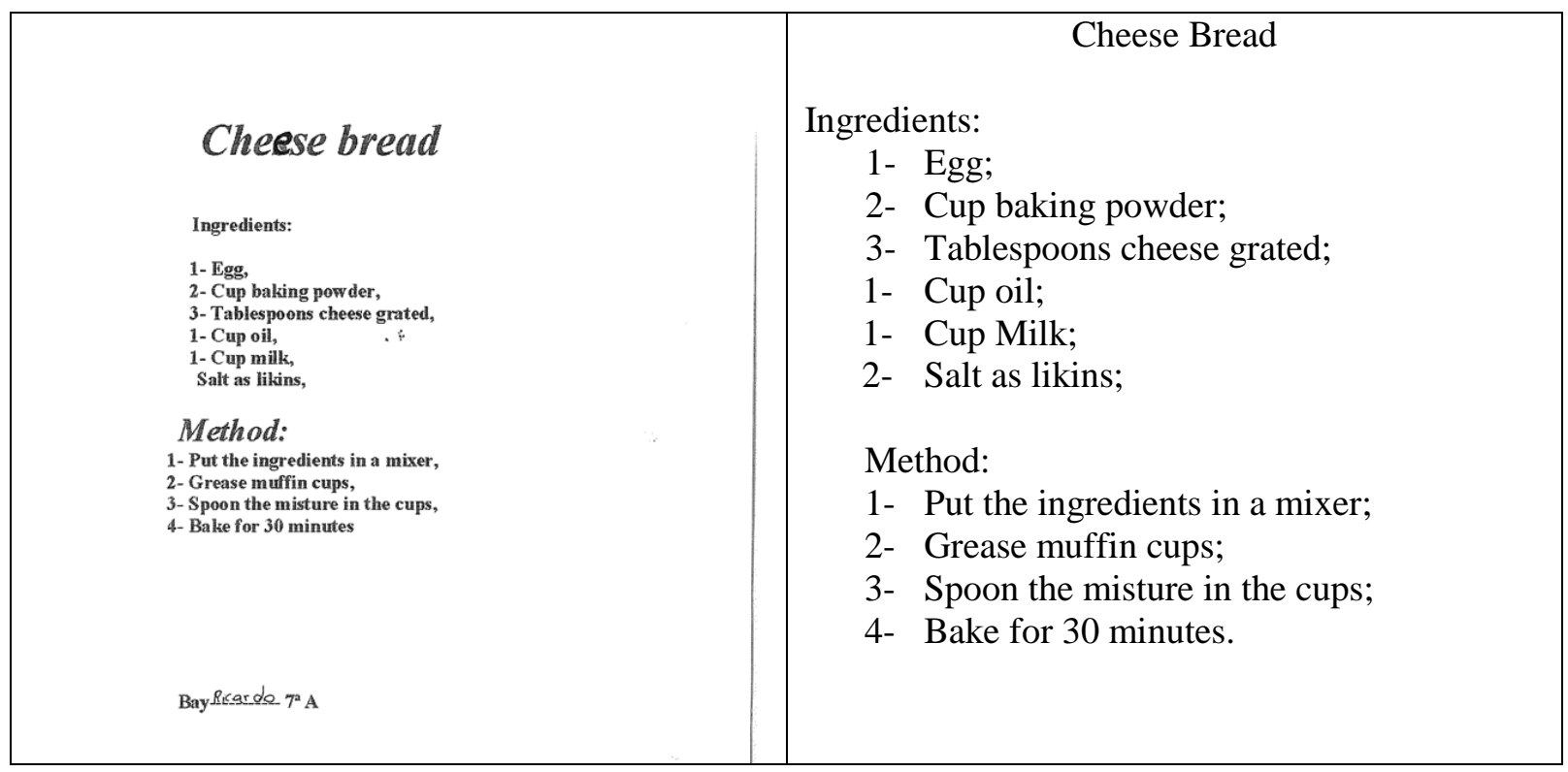

Figura 3: Versão final da receita do aluno 


\begin{tabular}{|l|l|}
\hline Lista de constatação & $\begin{array}{l}\text { Análise da versão final da receita do aluno a } \\
\text { partir da lista de constatação }\end{array}$ \\
\hline $\begin{array}{l}\text { Objetivo de fazer o destinatário agir de uma } \\
\text { determinada maneira (seguir os passos da receita) }\end{array}$ & Sim \\
\hline $\begin{array}{l}\text { Partes constitutivas essenciais: nome da receita; } \\
\text { lista de ingredientes com quantidade necessária } \\
\text { (que aparece antes do ingrediente, seguida por ele } \\
\text { sem a preposição de ligação de); modo de } \\
\text { preparo. }\end{array}$ & Presça de todos os itens essenciais. \\
\hline $\begin{array}{l}\text { Elementos não essenciais (autor da receita, o } \\
\text { tempo de preparo, o grau de dificuldade, a } \\
\text { quantidade de porções e uma figura ilustrativa). }\end{array}$ & Ausência de itens não essenciais. \\
\hline Uso de imperativo no modo de preparo. & Imperativo empregado sem dificuldades. \\
\hline Uso de léxico & Léxico mais apropriado, apesar da influência da \\
língua materna.
\end{tabular}

Quadro 3: Análise da produção final da receita do aluno a partir da lista de constatação

Na primeira versão produzida, o aluno havia apresentado dificuldades com a língua e era visível o uso do dicionário e tradução literal. $\mathrm{Na}$ segunda versão, há uma melhora significativa com relação a esse aspecto. O léxico utilizado pelo aluno é mais apropriado assim como a maneira com que as instruções são construídas, sem dificuldade no uso do imperativo.

$\mathrm{O}$ fato de ter estudado uma receita de muffin certamente colaborou para que sua produção fosse escrita de forma tão apropriada já que há muitas similaridades entre ambas. De qualquer maneira, isso demonstra que o aluno conseguiu servir-se dos conhecimentos apreendidos ao longo da SD para refazer seu texto. Mesmo que tenha recorrido ao material como apoio, ele próprio teve discernimento para produzir um texto adequado à situação.

Cremos que sua produção final é uma demonstração da importância de um trabalho com a língua em uso para contribuir para o desenvolvimento das capacidades de linguagem dos aprendizes.

Para finalizar a análise, a produção final da receita de arroz dos alunos em grupo é apresentada e discutida.

\begin{tabular}{|c|c|}
\hline 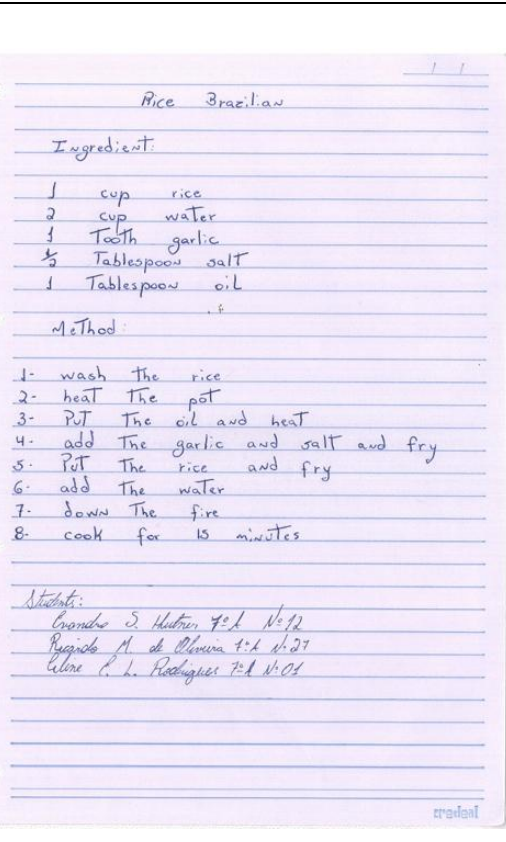 & $\begin{array}{l}\text { Rice Brazilian } \\
\text { Ingredient: } \\
1 \text { cup Rice } \\
2 \text { cup water } \\
1 \text { tooth garlic } \\
1 / 2 \text { tablespoon salt } \\
1 \text { tablespoon oil } \\
\text { Method } \\
\text { 1- Wash the Rice } \\
\text { 2- Heat a pot } \\
\text { 3- Put the oil and heat } \\
\text { 4- Add the garlic and salt and fry } \\
5-\text { Put the Rice and fry } \\
6-\text { Add the water } \\
\text { 7- Down the fire } \\
\text { 8- Cook for 15 minutes }\end{array}$ \\
\hline
\end{tabular}

Figura 4: Receita de arroz 2 produzida por alunos em grupo 


\begin{tabular}{|c|c|}
\hline Lista de constatação & $\begin{array}{l}\text { Análise da produção final da receita de arroz a } \\
\text { partir da lista }\end{array}$ \\
\hline $\begin{array}{l}\text { Objetivo de fazer o destinatário agir de uma } \\
\text { determinada maneira (seguir os passos da receita) }\end{array}$ & Produção parcialmente adequada ao contexto. \\
\hline $\begin{array}{l}\text { Partes constitutivas essenciais: nome da receita; } \\
\text { lista de ingredientes com quantidade necessária } \\
\text { (que aparece antes do ingrediente, seguida por ele } \\
\text { sem a preposição de ligação de); modo de } \\
\text { preparo. }\end{array}$ & Contemplação de todos os itens essenciais. \\
\hline $\begin{array}{l}\text { Elementos não essenciais (autor da receita, o } \\
\text { tempo de preparo, o grau de dificuldade, a } \\
\text { quantidade de porções e uma figura ilustrativa) }\end{array}$ & Ausência de itens não essenciais. \\
\hline Uso de imperativo no modo de preparo. & $\begin{array}{l}\text { Emprego adequado do imperativo para dar } \\
\text { instruções. Contudo, faltam explicações mais } \\
\text { detalhadas, que contribuam efetivamente com um } \\
\text { leitor que não sabe cozinhar arroz. }\end{array}$ \\
\hline Uso do léxico & Léxico parcialmente inapropriado \\
\hline
\end{tabular}

Já na primeira versão, os alunos não haviam apresentado muitas dificuldades para a produção da receita de arroz. Entretanto, é visível o desenvolvimento possibilitado ao longo da SD. Na receita inicial, a tradução literal foi evidente ao contrário da versão final em que o léxico visto nas receitas estudadas e nas atividades realizadas está presente, sendo um exemplo a substituição de "mode of prepare" por "Method". Também é notável como as instruções estão mais explicitadas, separadas passo-a-passo, com o uso apropriado do imperativo. Há ainda várias inadequações com itens lexicais como garlic choves em vez de tooth garlic, Heat a pan em vez de Heat a pot entre outros. A maior dificuldade parece estar na construção das orações. Por exemplo, o primeiro procedimento Wash the Rice deveria ser acompanhado de um complemento como "Wash the rice until the water runs clear" para possibilitar a compreensão do leitor que não sabe cozinhar arroz do modo descrito.

Com a análise, concluímos que houve aprimoramento nas produções e que possivelmente as atividades ocorridas ao longo da SD contribuíram para o desenvolvimento das capacidades de linguagem dos aprendizes.

\section{Considerações finais}

Nosso texto teve por objetivo ilustrar uma possibilidade de trabalho com gêneros textuais em sala de aula sugerida por Schneuwly e Dolz (2004) a partir dos princípios do ISD (BRONCKART, 2003). A proposta defende o emprego de SD que busca propiciar o desenvolvimento de capacidades de linguagem necessárias para agir em contextos específicos.

A SD que investigamos teve foco no gênero receitas culinárias que, a principio, pode parecer trivial e desinteressante para alunos de $7^{\mathrm{a}}$ série. Entretanto, no contexto em que ela foi aplicada, se mostrou apropriada e motivadora tendo em vista o projeto de troca de correspondências em andamento e a possibilidade de produção de um livro de receitas a ser trocado com norte-americanos.

O material foi constituído por sete partes que buscaram trabalhar as quatro capacidades de linguagem envolvidas de forma engrenada para que os alunos tivessem condições de compreender e produzir receitas em língua inglesa, além de refletir sobre hábitos alimentares, influência sócioeconômico-culturais, maneiras de dizer, de ser, como sugere Brait (2010).

O momento de sensibilização foi muito agradável e os alunos se entusiasmaram com a ideia de produzir um livro de receitas. Assim, o trabalho todo foi facilitado e as aulas foram razoavelmente produtivas tanto para o desenvolvimento da compreensão quanto da produção de receitas.

$\mathrm{O}$ envolvimento da família e o relato dos alunos dos testes que fizeram com as receitas em casa são apontados por nós como pontos positivos da SD, já que revelam que as receitas não foram tomadas exclusivamente como textos a serem estudados, mas sim como oportunidade de aprendizagem e desenvolvimento.

O diálogo propiciado pelas receitas selecionadas pode ser visto como propiciadora do desenvolvimento da capacidade de significação dos 
estudantes. Como exemplo, citamos a discussão sobre a receita mais estranha. Para praticamente cem por cento do grupo, "guacamole" foi considerada a receita estranha por ser um salgado feito com abacate, ingrediente que, para eles deve ser utilizado para sobremesas ou frapês. Nesse momento, a conversa possibilitou o conhecimento de hábitos de outras culturas e o reconhecimento de que abacate com açucar é comum apenas no Brasil. Em outro momento, a conversa sobre diferentes medidas se mostrou esclarecedora aos alunos, que tinham a ideia de que todos os povos serviam-se de um único sistema de medidas.

Ponderamos que discussões como essas auxiliam o desenvolvimento da capacidade de significação ao aguçar o senso de compreensão, respeito e de criticidade dos alunos com relação a si próprios e aos outros.

Com relação às produções, avaliamos que as atividades trouxeram subsídios para o desenvolvimento de capacidades de linguagem necessárias para esse agir e que, coerentemente com os resultados iniciais, muitas atividades focaram em aspectos linguístico-discursivos, possibilitando que os aprendizes se apropriassem de conhecimentos necessários e as versões finais apresentassem melhoras significativas se constrastadas com as versões iniciais.

Dessa maneira, finalizamos corroborando que a proposta de trabalho com SD no ensino de línguas adicionais pode ser produtiva e colaborar com o desenvolvimento do aluno para a comunicação efetiva e consciente.

\section{Notas}

1 Por cidade-irmã entende-se um acordo firmado entre duas cidades para o desenvolvimento de projetos em diferentes áreas, buscando amizade, crescimento cultural e econômico. Um dos projetos desenvolvidos entre as duas cidades citadas é do de troca de correspondências entre alunos das escolas públicas.

2 Tal projeto foi investigado e constitui a tese de doutoramento de uma das autoras, sob a orientação da outra autora. Defendida em 2009, na Universidade Estadual de Londrina, a tese é intitulada $O$ desenvolvimento da escrita em língua inglesa com o uso de sequências didáticas contextualizadas em um projeto de troca de correspondências.

3 Lista de constatação é uma lista com as características do gênero estudado que serve de guia aos alunos enquanto estão apreendendo-o.

\section{Referências}

BEATO-CANATO, A. P. M. B. Cartas de apresentação para pen pal: descrição do contexto de produção e da infra-estrutura global de textos produzidos por estudantes brasileiros, norteamericanos e eslovacos. Anais...III SIGET (Simpósio Internacional de Estudos de Gêneros Textuais). Santa Maria, 2005.

BEATO-CANATO, A. P. M. O desenvolvimento da escrita em língua inglesa com o uso de sequências didáticas contextualizadas em um projeto de troca de correspondências. 2009. 307f. Tese (Doutorado em Estudos da Linguagem) - Universidade Estadual de Londrina, 2009.

BRAIT, B. Literatura e outras linguagens. São Paulo: Contexto, 2010.

BRONCKART, J.-P. Seqüências e outras formas de planificação. In: Atividade de linguagem, textos e discursos: por um interacionismo sóciodiscursivo. Trad. Anna Raquel Machado, Péricles Cunha. São Paulo: EDUC, 2003, cap. 6, p. 217 248.

CRISTOVÃO, V. L. L. Modelos didáticos de gênero: uma abordagem para o ensino de língua estrangeira. Londrina: Uel, 2007.

CRISTOVÃO, V. L. L. Sequências didáticas para o ensino de línguas. In: _. O livro didático de língua estrangeira: múltiplas perspectivas. Mercado de Letras, 2009.

CRISTOVÃO, V. L. L.; NASCIMENTO, E. L. (Orgs.) Gêneros textuais: teoria e prática. Londrina: Moriá, 2004.

CRISTOVÃO, V. L. L.; NASCIMENTO, E. L. (Orgs.) Gêneros textuais: teoria e prática II. Palmas e União da Vitória, PR: Kaygangue, 2005.

CRISTOVÃO, V. L. L.. Gêneros e ensino de leitura em LE: modelos didáticos de gêneros na construção e avaliação de material didático. 2002. Tese (Doutorado em Linguística Aplicada e Estudos da Linguagem.) - Pontifícia Universidade Católica de 
São Paulo, PUC/SP.

CRISTOVÃO V. L. L.; STUTZ, L. Sequências didáticas: semelhanças e especificidades no contexto francófono como L1 e no contexto brasileiro como LE. In: SZUNDY, P. T. C.; ARAÚJO, J. C.; NICOLAIDES, C. S.; SILVA, K. A. da. Linguística Aplicada e Sociedade: ensino e aprendizagem de línguas no contexto brasileiro. Campinas: Pontes Editores, 2011, p. 17-39.

CRISTOVÃO, V. L. L. O uso do meio virtual em práticas sociais de leitura e escrita na educação (inicial e continuada) de professores de inglês. (prelo)

DIAS, R.; DELL'ISOLA, R. L. P. Gêneros textuais - teoria e prática de ensino em LE. Campinas: Mercado de Letras, 2012.

DIONISIO, A. P.; MACHADO, A. R.; BEZERRA, M. A. (Orgs.). Gêneros textuais \& Ensino. 4a. ed. Rio de Janeiro: Lucerna, 2005.

DOLZ, J.; PASQUIER, A.; BRONCKART, J-P. L'acquisition des discours: emergence d'une compétence ou apprentissage de capacités langagières? Études de Linguistique Appliquée, 102, p.23-37, 1993. p.23-37.

DOLZ, J.; SCHNEUWLY, B. Pour un enseignement de l'oral: iniciation aux genres formals à le école. Paris : ESF Editeur, 1998.

FERRARINI, M. A. O gênero textual conto de fadas para o ensino de produção escrita em língua inglesa. 2009. Dissertação (Mestrado em Estudos da Linguagem) - Universidade Estadual de Londrina, 2009.

FERRARINI, M. A. Written production and evaluation: a challenge for teachers and students. In: GIMENEZ, T.; CRISTOVÃO, V. L. L. (Org.). Teaching English in context: contextualizando o ensino de inglês. Londrina: UEL, 2006. p. 67-84.

KARWOSKI, A. M.; GAYDECZKA, B.; BRITO, K. S. (Orgs.). Gêneros textuais: reflexões e ensino. Palmas e União da Vitória, PR: Kaygangue, 2005.

PETRECHE, C. R. C. A sequência didática nas aulas de língua inglesa no ensino médio $e$ desenvolvimento de capacidades de linguagem. 2008. Dissertação (Mestrado em Estudos da Linguagem) - Universidade Estadual de Londrina, UEL, Brasil.

SCHNEUWLY, B.; DOLZ, J. et al. Gêneros orais e escritos na escola. Trad. e org. Roxane Rojo e Glaís Sales Cordeiro. Campinas: Mercado de Letras, 2004.

\section{Sobre as autoras:}

Ana Paula Marques Beato-Canato: Mestre (2003) e Doutora (2009) em Estudos da Linguagem pela Universidade Estadual de Londrina (UEL) e graduada (1998) em Letras pela Universidade Estadual Paulista Júlio de Mesquita Filho (UNESP-Assis/SP). Tem experiência na área de Linguística Aplicada. Professora do Programa Interdisciplinar de Pos-Graduação em Linguística Aplicada da UFRJ e professora adjunta de língua inglesa no Departamento de Anglo-Germânicas.

Vera Lúcia Lopes Cristovão: Professora associada da Universidade Estadual de Londrina (UEL), membro do Programa de Pós Graduação em Estudos da Linguagem (PPGEL-UEL). É Mestre (1996) e Doutora (2002) em Linguística Aplicada e Estudos da Linguagem pelo Programa de Pós-Graduação da PUC-SP.

Artigo recebido em novembro de 2013

Artigo aprovado em março de 2014 
